Bundesgesundheitsbl $2021 \cdot 64: 1026$

https://doi.org/10.1007/s00103-021-03326-9

Online publiziert: 6. Mai 2021

(c) Der/die Autor(en) 2021

Alejandro Cornejo Müller · Benjamin Wachtler - Thomas Lampert

FG28 Soziale Determinanten der Gesundheit, Robert Koch-Institut, Berlin, Deutschland

\title{
Erratum zu: Digital Divide - Soziale Unterschiede in der Nutzung digitaler Gesundheitsangebote
}

\section{Erratum zu:}

Bundesgesundheitsbl 2019

https://doi.org/10.1007/s00103-019-

03081-y

Der Artikel Digital Divide - Soziale Unterschiede in der Nutzung digitaler Gesundheitsangebote von Alejandro Cornejo Müller, Benjamin Wachtler und Thomas Lampert wurde ursprünglich am 08.01.2020 ohne Open Access online auf der Internetplattform des Verlags publiziert. Die Autoren haben sich jedoch nachträglich für eine OpenAccess-Veröffentlichung entschieden. Das Urheberrecht des Artikels wurde deshalb am 29.03.2021 in (C) The Author(s) 2020 geändert. Der Artikel wird nun unter der Creative-Commons-Namensnennung 4.0 International Lizenz veröffentlicht, welche die Nutzung, Vervielfältigung, Bearbeitung, Verbreitung und Wiedergabe in jeglichem Medium und Format erlaubt, sofern Sie den/die ursprünglichen Autor(en) und die Quelle ordnungsgemäß nennen, einen Link zur Creative-Commons-Lizenz beifügen und angeben, ob Änderungen vorgenommen wurden.

Die in diesem Artikel enthaltenen Bilder und sonstiges Drittmaterial unterliegen ebenfalls der genannten CreativeCommons-Lizenz, sofern sich aus der Abbildungslegende nichts anderes ergibt. Sofern das betreffende Material nicht unter der genannten Creative-CommonsLizenz steht und die betreffende Handlung nicht nach gesetzlichen Vorschriften erlaubt ist, ist für die oben aufgeführten Weiterverwendungen des Materials die
Einwilligung des jeweiligen Rechteinhabers einzuholen.

Weitere Details zur Lizenz entnehmen Sie bitte der Lizenzinformation aufhttp:// creativecommons.org/licenses/by/4.0/ deed.de.

\section{Korrespondenzadresse}

PD Dr. Thomas Lampert

FG28 Soziale Determinanten der Gesundheit, Robert Koch-Institut

General-Pape-Str. 62-66, 12101 Berlin,

Deutschland

t.lampert@rki.de

Funding. Open Access funding enabled and organized by Projekt DEAL.

Open Access. Dieser Artikel wird unter der Creative Commons Namensnennung 4.0 International Lizenz veröffentlicht, welche die Nutzung, Vervielfältigung, Bearbeitung, Verbreitung und Wiedergabe in jeglichem Medium und Format erlaubt, sofern Sie den/die ursprünglichen Autor(en) und die Quelle ordnungsgemäß nennen, einen Link zur Creative Commons Lizenz beifügen und angeben, ob Änderungen vorgenommen wurden.

Die in diesem Artikel enthaltenen Bilder und sonstiges Drittmaterial unterliegen ebenfalls der genannten Creative Commons Lizenz, sofern sich aus der Abbildungslegende nichts anderes ergibt. Sofern das betreffende Material nicht unter der genannten Creative Commons Lizenz steht und die betreffende Handlung nicht nach gesetzlichen Vorschriften erlaubt ist, ist für die oben aufgeführten Weiterverwendungen des $\mathrm{Ma}$ terials die Einwilligung des jeweiligen Rechteinhabers einzuholen.

Weitere Details zur Lizenz entnehmen Sie bitte der Lizenzinformation auf http://creativecommons.org/ licenses/by/4.0/deed.de.

Die Online-Version des Originalartikels ist unter https://doi.org/10.1007/s00103-019-03081-y zu finden. 